03

\title{
Особенности разрушения гомогенных и композиционных преград при высокоскоростном взаимодействии со стержневыми ударниками
}

\author{
(C) В.М. Захаров, А.Н. Табаченко, С.А. Афранасьева \\ Научно-исследовательский институт прикладной математики и механики Национального исследовательского Томского \\ государственного университета, \\ 634050 Томск, Россия \\ e-mail: zakharov_vm@list.ru
}

(Поступило в Редакцию 21 ноября 2016 г.)

\begin{abstract}
Экспериментально исследуется разрушение гомогенных и композиционных, имеющих средний металлокерамический слой, преград при взаимодействии с ударниками из сплава ВНЖ-90. Сравнимость результатов для разных типов преград обеспечивалась на основе весовой эквивалентности - равенства веса по толщине для единицы площади преграды. Начальная скорость взаимодействия - от 0.8 до $1.1 \mathrm{~km} / \mathrm{s}$. Высокоскоростной кинокамерой осуществлялась регистрация процесса от момента подхода ударника до формирования развитого осколочного потока за преградой. Обработкой кинограмм построены зависимости „Перемещение-время“ для характерных плоскостей мишенной обстановки - заднего торца ударника, тыльной поверхности преграды. Анализ этих зависимостей позволил выявить особенности разрушения преград. Отмечены сильные различия в геометрии зон разрушения и динамике процесса для монолитных и композиционных преград.
\end{abstract}

DOI: 10.21883/JTF.2017.07.44669.2106

\section{Введение}

В конструкциях изделий, подвергаемых интенсивным ударным нагрузкам, активно используются различные композиционные материалы с повышенными прочностными характеристиками. Подобные конструкции могут использоваться в качестве как средств поражения, так и средств защиты. Важным направлением исследований является анализ разрушений конструкций с композиционными материалами в практически значимых условиях ударных нагрузок [1,2]. Для таких условий наиболее достоверны экспериментальные данные по испытаниям конкретных конструктивных схем изделий.

Целью настоящей работы является исследование характера разрушения преград при высокоскоростном ударном взаимодействии высокоплотных стержневых ударников с гомогенными стальными и составными преградами, содержащими между стальными слоями металлокерамический слой.

\section{Методика эксперимента}

Эксперимент проводился с ударниками, изготовленными из сплава ВНЖ-90 в состоянии поставки. Диаметр ударника $d_{0}=5.0 \mathrm{~mm}$, длина $-5 d_{0}$. Устойчивость ударников на траектории обеспечивалась с помощью конического стабилизатора, изготовленного из алюминиевого сплава Д16. Ведение по каналу ствола пороховой баллистической установки калибром $13.2 \mathrm{~mm}$ (ПБУ-13) осуществлялось с помощью отделяемого поддона толкающего типа. Ведущие секторы поддона изготавливались из капролона, разрезной толкающий диск - из Д16.
Опыты проводились по преградам двух типов: гомогенным и композиционным. Гомогенная преграда - диск из стали 45 толщиной $b=12.4 \mathrm{~mm}=2.48 d_{0}$, диаметр диска $60 \mathrm{~mm}$. Композиционная преграда - сборка из трех дисков: $\left(b_{1}+b_{2}+b_{3}\right)=3 d_{0}$. Диски $b_{1}$ и $b_{3}$ изготавливались из того же прутка стали 45 толщиной $b_{1}=b_{3}=d_{0}$. Средний слой сборки представлял собой пластину из керамики $\left(\mathrm{TiB}_{2}+\mathrm{B}_{4} \mathrm{C}\right)$ с металлической связующей. Толщина среднего слоя также $b_{2}=d_{0}$.

Композиционный металлокерамический материал на основе диборида титана и карбида бора $\left(\mathrm{TiB}_{2}+\mathrm{B}_{4} \mathrm{C}\right)$ с металлической связующей был получен методом самораспространяющегося высокотемпературного синтеза (СВC) с применением деформационного компактирования конечных продуктов реакции. В качестве экзотермических компонент использовали поликристаллический бор и титан марки ПТМ. Плотность металлокерамики составляла $3.81 \mathrm{~g} / \mathrm{sm}^{3}$. Свойства исследуемой металлокерамики изучались в работе [3]. Конечные размеры защитных плиток достигались путем шлифовки СВС заготовок алмазным инструментом.

Соприкасающиеся поверхности всех дисков шлифовались и жестко стягивались болтами по наружному контуру дисков. В каждую сборку производился один опыт. Эквивалентность по весу выражалась условием $[b=2.4 \mathrm{~mm}]_{\mathrm{st} 45}=\left[b_{2}=5 \mathrm{~mm}\right]_{\text {composit. }}$ То есть гомогенная и композиционная преграды имели одинаковый вес по толщине (на единицу площади), что позволяло производить сравнительный анализ стойкости преград.

Скорость ударников определялась индукционным измерителем с погрешностью не более $0.2 \%$. В качестве согласующе-формирующего устройства и устройства синхронизации запуска регистрирующей аппарату- 


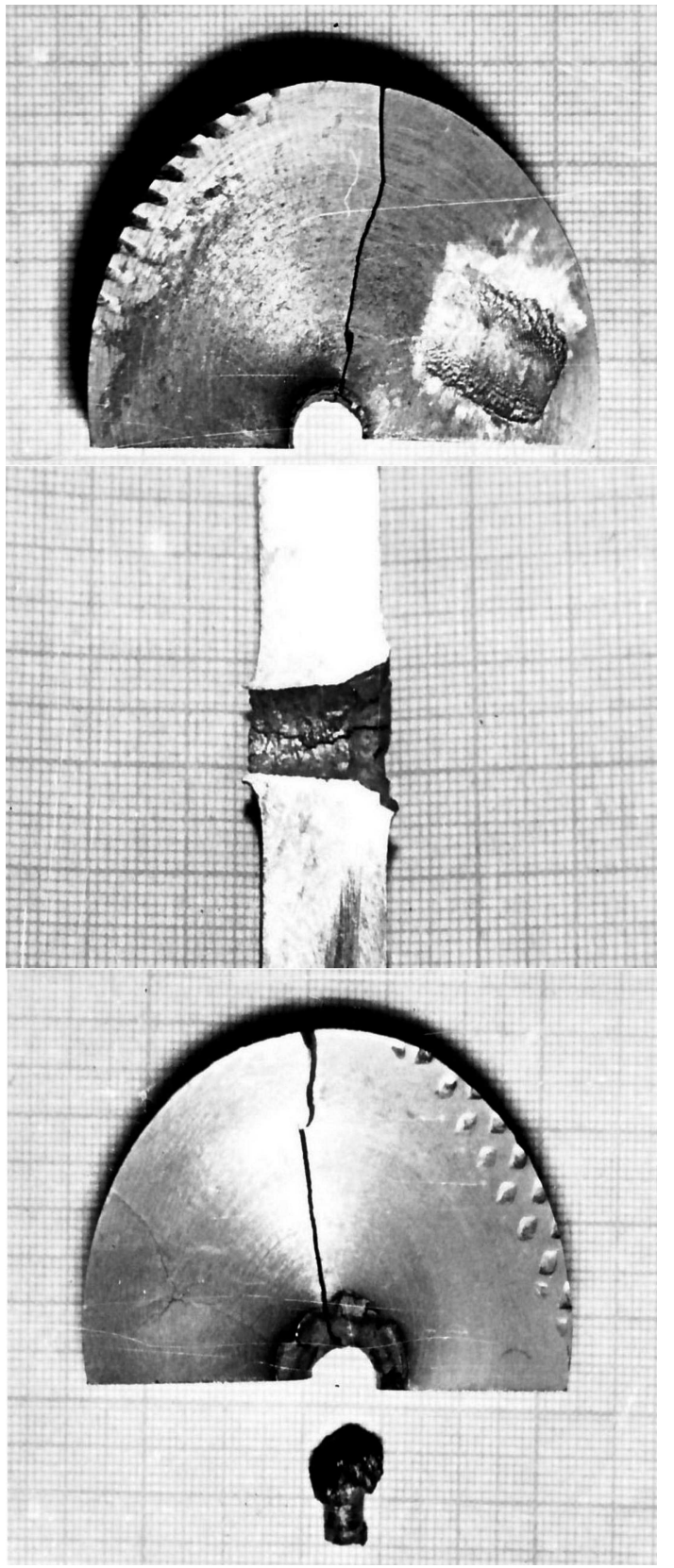

Рис. 1. Гомогенная преграда после взаимодействия с высокоплотным ударником при скорости $1061 \mathrm{~m} / \mathrm{s}$ : сверху вниз лицевая поверхность преграды, осевой разрез пробоины, тыльная поверхность преграды и остаток ударника.

ры использовался специально разработанный прибор. Регистрация динамики процесса проникания и пробития осуществлялась камерой ЖЛВ-2. Камера находилась вне зоны ПБУ-13 и наводилась на область регистрации с помощью поворотного зеркала. Расшифровка изображений на фотопленке производилась с помощью реперов, которые представляли собой цилиндры малого диаметра определенной длины; обычно реперы располагались в плоскости стрельбы соосно на лицевой и тыльной поверхностях преграды.

\section{Характер разрушения преград}

Анализ сборок после опытов показал, что характер разрушения гомогенной и композиционной преград различен. На рис. 1 представлены фотографии гомогенной преграды после пробития ее ударником. На рис. 2 приведены фрагменты композиционной преграды.

Результаты эксперимента показали, что практически при одной и той же скорости удара $(\sim 1070 \mathrm{~m} / \mathrm{s})$ срабатывание ударника на гомогенной и композиционной преградах получается близким: длина остатка ударника равна $2.20 d_{0}$ и $2.24 d_{0}$ для гомогенной и композиционной преград соответственно. Лицевое разрушение на преградах также является одинаковым: входной диаметр пробоины равен $1.64 d_{0}$ в обоих случаях. Разрушение же тыльных поверхностей преград существенно различно. Для наглядности профиль пробоин в обеих преградах реконструирован графически и показан на рис. 3 .

Различия наблюдаются уже в геометрии пробоин первого слоя: так, диаметр пробоины на уровне его тыльной поверхности составляет $3 d_{0}$ для гомогенной и $1.8 d_{0}$ для композиционной преград. Во всех случаях пробитие гомогенной преграды происходит с образованием откола, в то время как в первом слое композиционной преграды откол не образуется. В этом проявляется эффект слоистости композиционной преграды: перераспределение давления на фронте волны сжатия на границе слоев
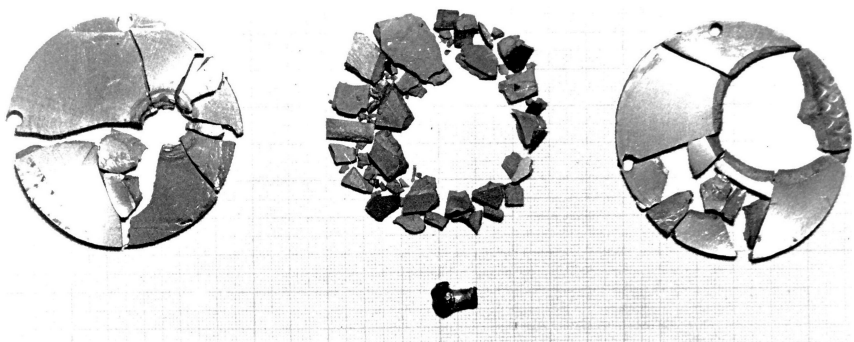

Рис. 2. Композиционная преграда после взаимодействия с высокоплотным ударником при скорости 1073 m/s: слева направо - тыльная поверхность первого стального слоя, осколки второго керамического слоя и остаток ударника, тыльная поверхность третьего стального слоя.

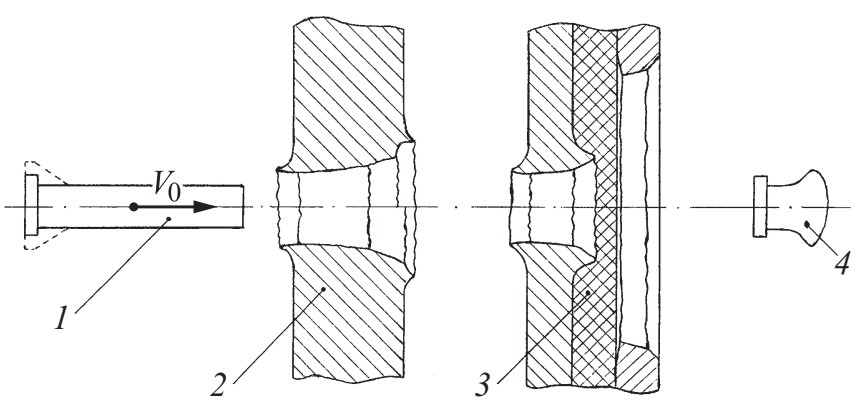

Рис. 3. Геометрия разрушения преград: 1 - исходная геометрия ударника, 2 - гомогенная преграда, 3 - композиционная преграда, 4 - конечная геометрия ударника. 


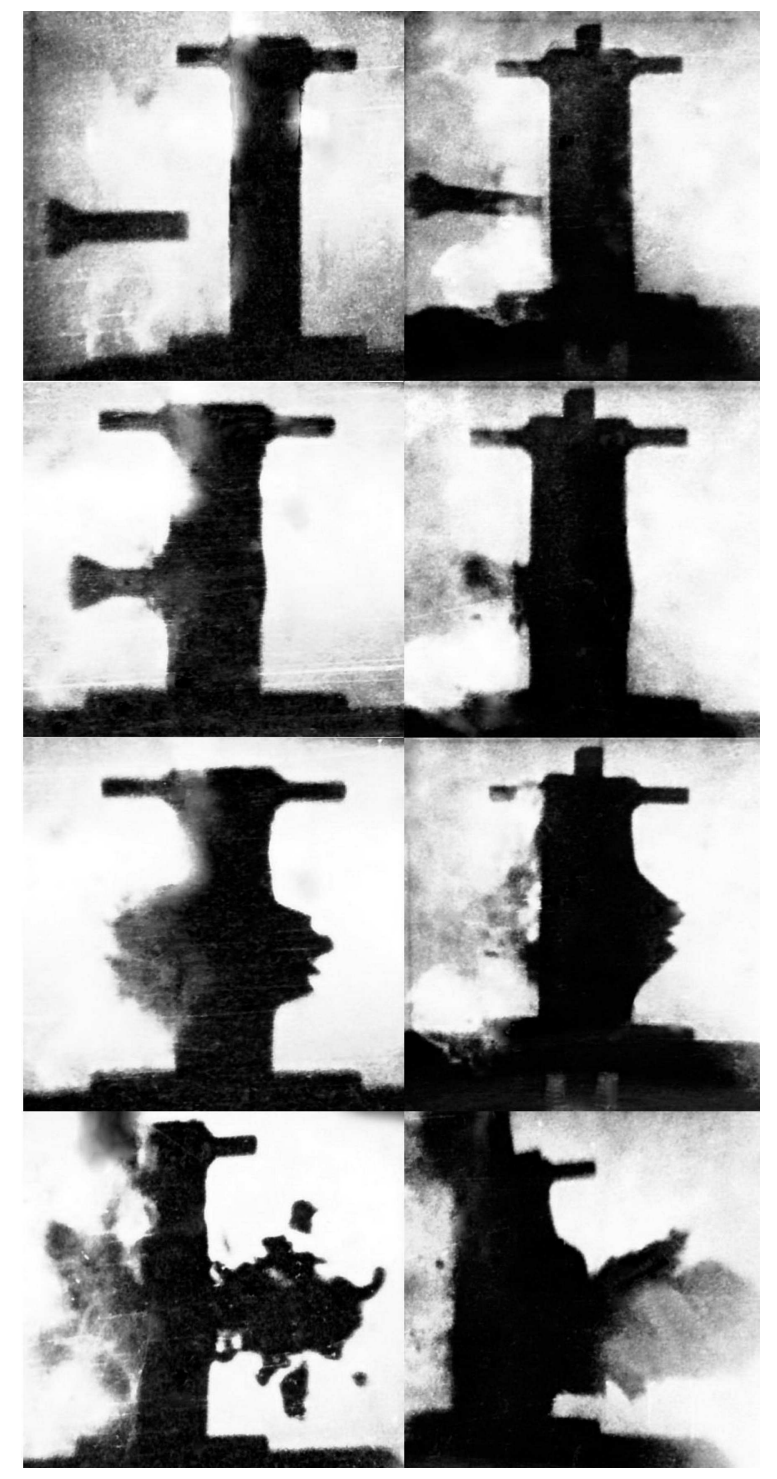

Рис. 4. Кадры киносъемки процесса взаимодействия высокоплотного ударника с преградами в различные моменты времени от начала соударения. Левый ряд - гомогенная преграда, сверху вниз, $\mu \mathrm{s:}(-8.3), 12.1,32.5,85.1$; правый ряд - композиционная преграда, сверху вниз, $\mu \mathrm{s:}(-1.8), 12.8$, 33.1, 82.4.

снижает интенсивность волны разгрузки в первом слое и откол не образуется.

Разрушение третьего стального слоя композиционной преграды носит характер „пролома“ и имеет значительные размеры: входной диаметр составляет $\sim 6 d_{0}$, а выходной $\sim 7 d_{0}$. Средний керамический слой хрупко разрушается (раскалывается) примерно в этом же объеме и его осколки составляют основную часть запреградного потока.

Катастрофический характер разрушения третьего слоя сборки есть следствие совместного воздействия на него движущегося ударника и осколков раскалывающегося керамического слоя. Отсюда следует, что для повышения защитных свойств композиционной преграды необходимо обеспечивать стойкость третьего слоя: увеличивать его толщину, использовать более пластичные материалы, придавая ему свойство основного защитного элемента конструкции.

\section{Анализ динамики процесса соударения}

На рис. 4 показан ряд кинокадров взаимодействия ударника с гомогенной и композиционной преградами. Обработкой данных высокоскоростной кинорегистрации были построены диаграммы $x(t)$, где $x$ - перемещение, $t$ - время. Анализировались подход ударника, движение его заднего торца при внедрении и развитие тыльного купола при пробитии преград.

На рис. 5 и 6 представлены графические зависимости для гомогенной и композиционной преград при нескольких начальных скоростях взаимодействия $V_{0}$. На рисунках обозначено положение начала координат в мишенной обстановке.

Графики показывают, что зависимости $x(t)$ для обоих типов преград подобны. Некоторую особенность можно отметить для торможения ударника: в случае гомогенной преграды движение заднего торца ударника при его внедрении происходит примерно с постоянной скоростью $V$, что подтверждает известную гипотезу об определяющем вкладе стационарной фазы в процессе

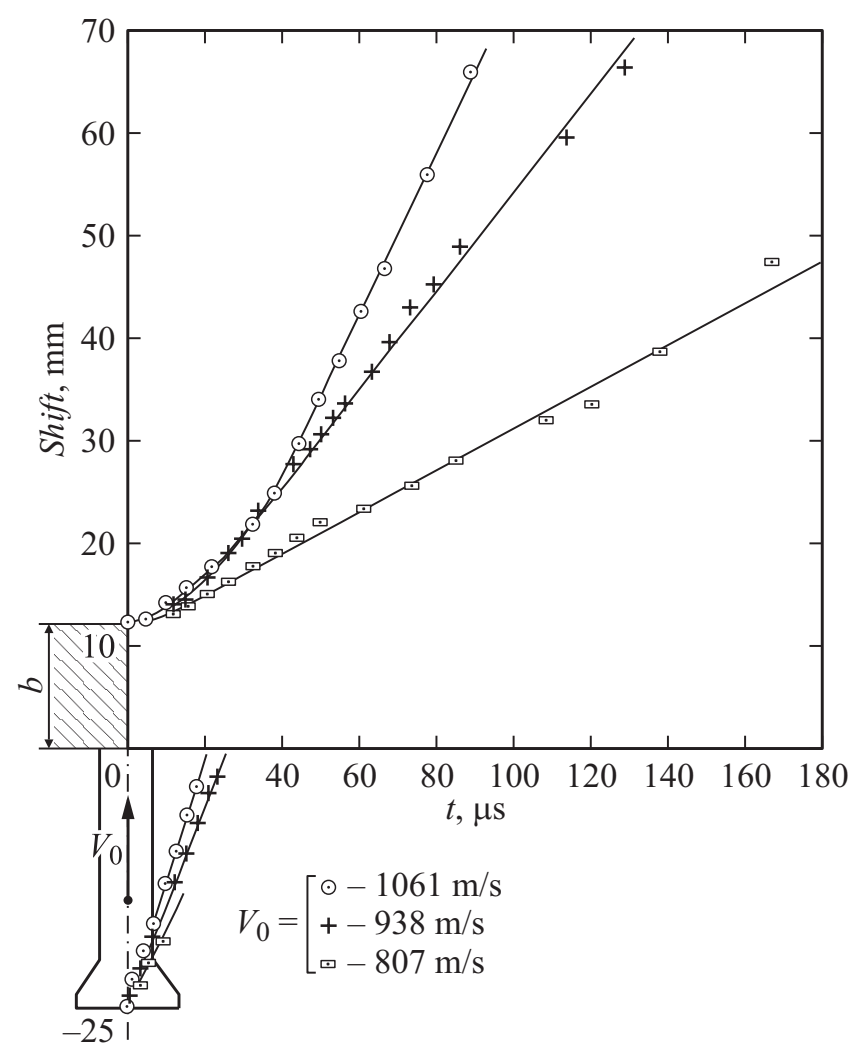

Рис. 5. Зависимости перемещений заднего торца ударника и тыльной поверхности гомогенной преграды от времени для различных начальных скоростей удара. 


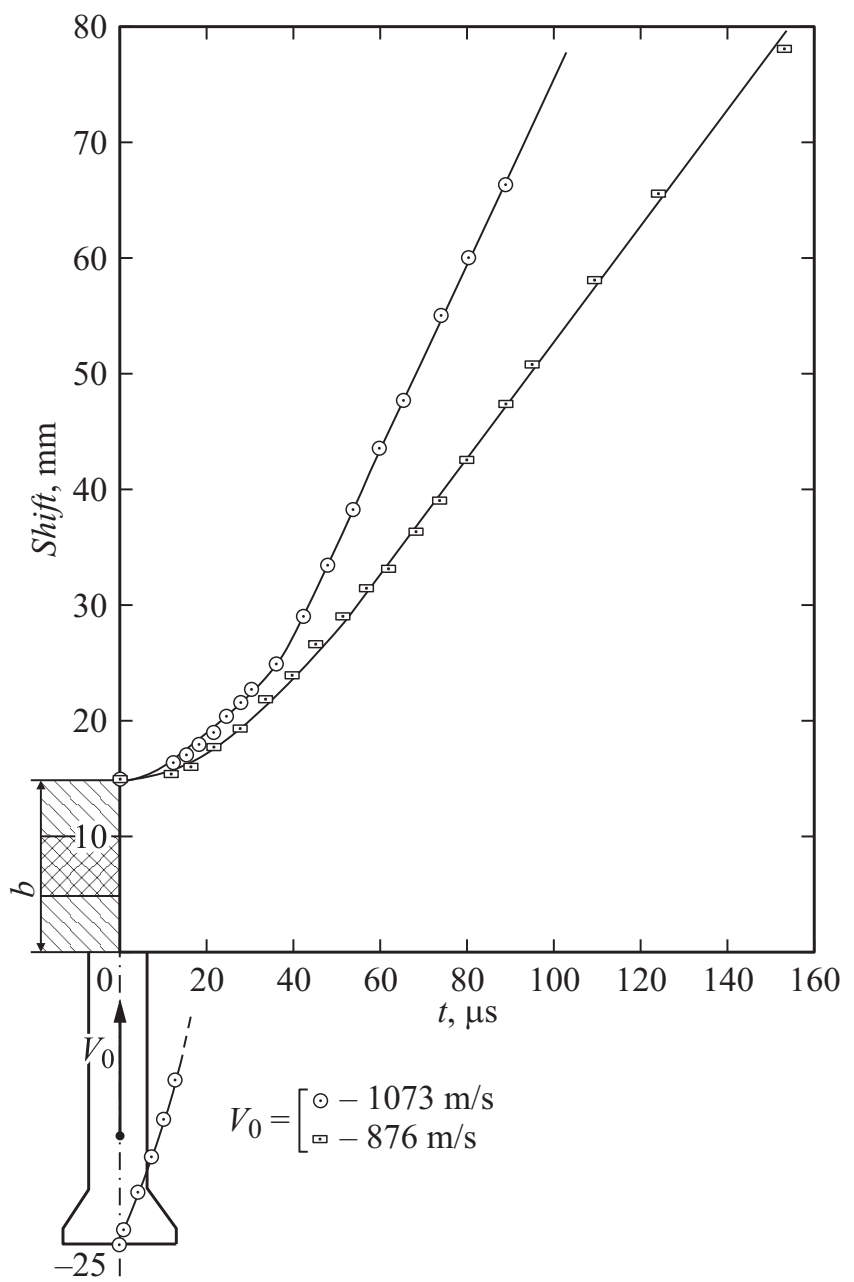

Рис. 6. Зависимости перемещений заднего торца ударника и тыльной поверхности композиционной преграды от времени для различных начальных скоростей удара.

проникания удлиненного ударника. Причем эта скорость находится в прямой зависимости от начальной скорости удара $V_{0}$ : чем больше $V_{0}$, тем больше и $V$.

В случае же композиционной преграды зависимость $x(t)$ для торца ударника имеет несколько иной вид. Эта зависимость нелинейная и обращена выпуклостью к оси $t$. То есть скорость заднего торца ударника в процессе проникания несколько возрастает. Эффект этот выражен не очень ярко, но заметен. Объяснение этого связано с воздействием ударника на жесткий средний керамический слой преграды: с одной стороны, это взаимодействие достаточно пластичного ударника с жесткой преградой, а с другой - это совместное по ходу движение системы „ударник-керамика“, приводящее к разрыву мягкого тыльного слоя сборки.

Движение тыльного купола при пробитии преград более наглядно можно оценить по зависимостям „перемещение-скорость удара“, построенным для фиксированных моментов времени от начала соударения. Эти графики для $t=60$ и $90 \mu \mathrm{s}$ приведены на рис. 7.
Графики показывают, что перемещение тыльного купола для монолитной преграды имеет более сильную зависимость от начальной скорости удара, чем для композиционной. При низких скоростях удара $\left(V_{0} \leq 1000 \mathrm{~m} / \mathrm{s}\right)$ перемещение потока за композиционной преградой более значительное, чем за монолитной, однако при $V_{0} \geq 1100 \mathrm{~m} / \mathrm{s}$ картина меняется на противоположную.

По кинограммам были сделаны оценки скорости запреградных потоков $V_{s}$ в фазе их развитого движения $(t=60-90 \mu \mathrm{s})$.

Характер зависимостей $V_{s}\left(V_{0}\right)$ подобен графикам на рис. 7, а именно с ростом $V_{0}$ скорость потока сильно возрастает, причем в большей степени для гомогенной преграды; так, при увеличении $V_{0}$ с 850 до $1050 \mathrm{~m} / \mathrm{s}$, т. е.

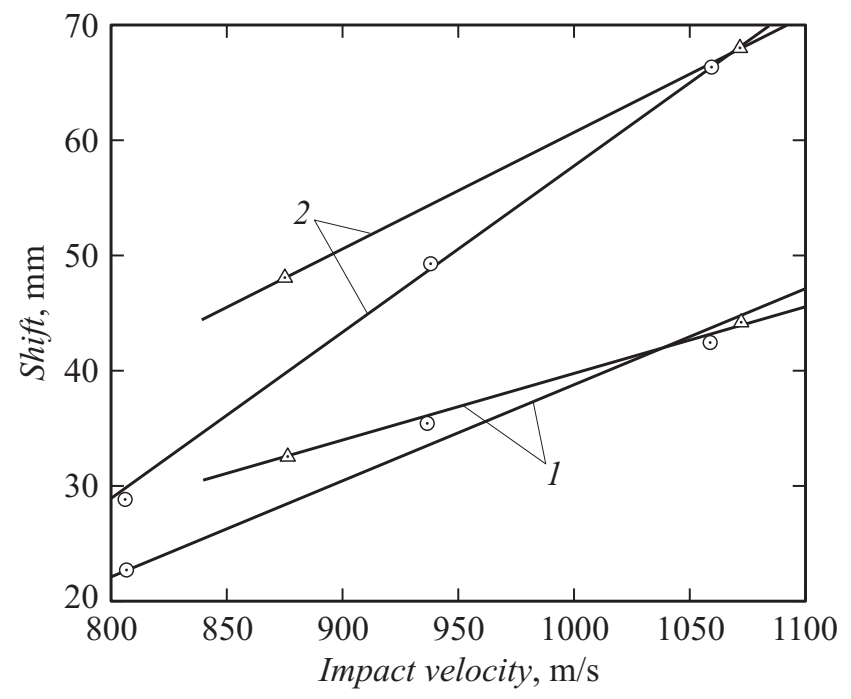

Рис. 7. Зависимость перемещения тыльного купола от начальной скорости удара в различные моменты времени от начала взаимодействия: $1-60 \mu \mathrm{s}, 2-90 \mu \mathrm{s} ; \odot-$ гомогенная преграда, $\triangle-$ композиционная преграда.

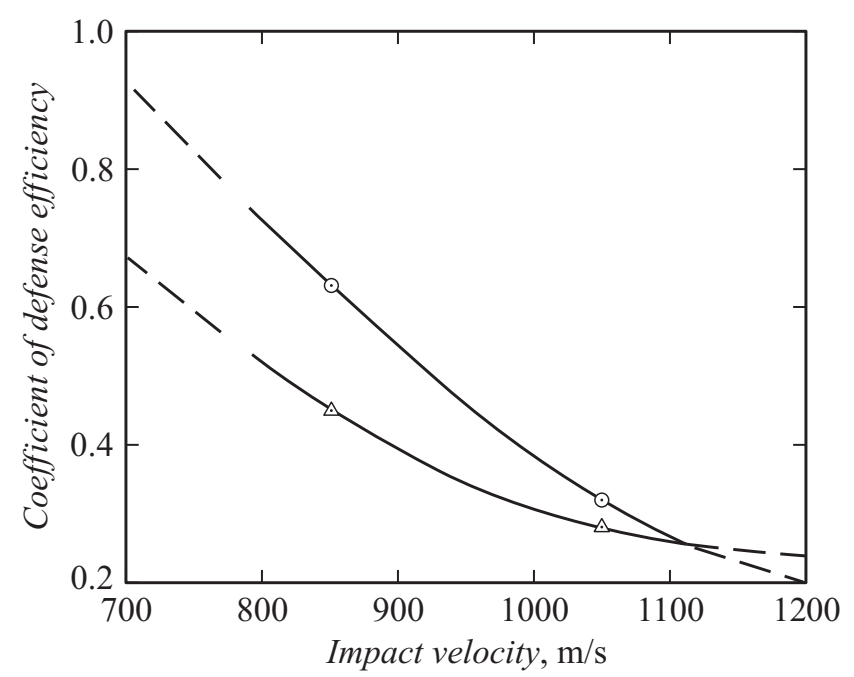

Рис. 8. Зависимость коэффициента эффективности защиты от начальной скорости удара: $\odot-$ гомогенная преграда, $\triangle-$ композиционная преграда. 
при увеличении на $\sim 24 \%$, скорость потока возросла на $\sim 140 \%$ для гомогенной и на $\sim 62 \%$ для композиционной преград. При низких $V_{0}$ скорость $V_{s}$ выше для композиционной преграды, но при $V_{0} \approx 1100 \mathrm{~m} / \mathrm{s}$ скорость потоков за обеими преградами получается одинаковой.

Для анализа эффективности защитных свойств исследуемых преград рассмотрим коэффициент эффективности защиты в виде $K_{e d}=\Delta V / V_{0}$, где $\Delta V=\left(V_{0}-V_{s}\right)-$ потеря скорости ударника при пробитии преград.

Граничные значения $K_{e d}$ определяются следующим образом: $K_{e d}=1$ - максимальное значение, достигается при $V_{0}$, равном пределу сквозного пробития преграды, и $K_{e d} \approx 0-$ минимальное значение, получается при значениях $V_{s}$, близких к $V_{0}$ (высокие скорости удара, тонкие и малопрочные преграды и т.п.).

Зависимость $K_{e d}$ для исследуемых преград приведена на рис. 8. Штрихами показана экстраполяция кривых в область предполагаемых граничных значений $K_{e d}$. Характер кривых также свидетельствует о том, что при высоких скоростях $V_{0} \geq 1100 \mathrm{~m} / \mathrm{s}$ композиционные преграды могут быть эффективнее гомогенных.

\section{Заключение}

Проведенные эксперименты позволили установить ряд особенностей процесса соударения, выявить характерные черты и получить конкретные оценки зон разрушения преград.

Отмечено, что сквозное разрушение стальной гомогенной преграды высокоплотным удлиненным ударником из сплава ВНЖ-90 происходит с образованием тыльного откола. В то же время при пробитии первого стального слоя композиционной преграды откол не образуется.

Средний керамический слой хрупко разрушается на многочисленные фрагменты, воздействующие совместно с ударником на тыльный стальной слой композиционной преграды. Такое воздействие приводит к разрыву тыльного слоя преграды на отдельные фрагменты.

С целью повышения защитных свойств композиционной преграды тыльный слой следует усиливать, предотвращая тем самым его катастрофическое разрушение.

Высокоскоростная киносъемка позволила провести анализ динамики процесса внедрения ударника и разрушения преграды. Сделаны оценки скорости запреградного потока для исследуемых преград.

Рассмотрение коэффициента эффективности защитных свойств преграды по относительной величине потери скорости при пробитии преград позволяет сделать вывод о более высоких защитных свойствах композиционных преград при скоростях встречи более $1100 \mathrm{~m} / \mathrm{s}$.

Результаты экспериментов могут быть использованы также для корректировки моделей сред и критериев их разрушения при численном моделировании процессов соударения.

\section{Список литературы}

[1] Физика ударных волн, горения, детонации, взрыва и неравновесных процессов. Коллективная монография / Под ред. В.А. Левина, Н.А. Фомина, В.Е. Фортова. Ч. 1. Минск: Институт тепло-массообмена им. А.В. Лыкова НАН Беларуси, 2014. С. 11-22.

[2] Zakharov V.M. // AIP Conf. Proceedings. AIP Publishing, 2016. Vol. 1698. P. 040008-1-040008-6.

[3] Белов Н.Н., Югов Н.Т., Афанасьева С.А., Табаченко А.Н., Коняев А.А., Толкачев В.Ф., Югов А.А. // ДАН. 2005. Т. 402. № 5. C. $617-622$. 